\title{
Isolation and Screening of Lignin and Cellulose Degrading Proficient Microbial Strains from Diverse Biotic Substrates Based on Qualitative Traits
}

\author{
S. Keerthana ${ }^{1}$, P. Kalaiselvi ${ }^{1 *}$, M. Maheshwari ${ }^{1}$ and T. Kalaiselvi ${ }^{2}$ \\ ${ }^{1}$ Department of Environmental Sciences, ${ }^{2}$ Department of Agricultural Microbiology, \\ TNAU, Tamil Nadu, Coimbatore, TN, India \\ *Corresponding author
}

\section{A B S T R A C T}

Lignocellulosic material is one of the substances resistant to degradation. The cellulose and lignin present in these materials have high molecular weight,

Keywords

Lignin, Cellulose,

Biodegradation,

Organic source,

Dominant strains

Article Info

Accepted:

07 June 2019

Available Online:

10 July 2019 structurally complex material consisting of various biologically stable linkages which are unable to breakdown. The utilization of biological method to degrade lignocellulose waste materials has been very effective and ecofriendly method. The present study was aimed to isolate lignocellulosic waste degrading bacterial and fungal strains from different organic sources. The degraded wood, degraded leaves, compost, termite gut were selected as a source. Enrichment of sample source was also done to isolate the microbial strains. Totally 20 bacterial colonies and 8 fungal colonies were isolated, from those 28 isolates only 2 bacterial and 2 fungal isolates confirmed as cellulose and lignin degraders through conformational test. The isolated 2 bacterial and 2 fungal strains were identified as Achromobacter sp., Pseudomonas sp., Aspergillus sp. and Fusarium sp. respectively, have having significant potential for using them in the treatment of lignin and cellulose degradation.

\section{Introduction}

Lignocellulose is one of the major sustainable, eco-friendly component predominantly found in terrestrial plants comprising half of the plant matter produced by photosynthesis Kamm et al., (2004) and Sergentani et al., (2016). These terrestrial plants fixes carbon into a macromolecular composite matrix which consists of three different types of polymers namely carbohydrate polymers including cellulose (35-50\%), hemicellulose (25-30\%) and aromatic polymers which includes lignin (25-30\%) (Ragauskas et al., 2006). Cellulose are linear polysaccharide of glucose with $\beta$-1, 4-glycosidic linkages. Plenty of cellulose raw materials have attracted experts and commercial for making commodities. Sadly, most of the cellulosic materials were often disposed of or burned 
which are the one of the causes for global warming. With the help of cellulose degrading system, the cellulose materials were transferred to glucose to multiutility products in a cheaper and biologically favoured way without causing effects to environment. Lignin content which protects cellulose; cellulose interweaving by hemicellulose; high crystallinity and degree of polymerization of cellulose and low accessible surface area of cellulose with strong fibre strength are the various factors responsible for its recalcitrant property. The conversion of these waste materials using microbes or with their enzymes has been an economically feasible process. The main advantages of using biological method over chemical pretreatment includes low energy requirement, mild reaction, high substrate specificity, product yield and maximum hydrolysis efficiency Mosier et al., (2005). Recently, there is a great deal and interest for bio-delignification processes Gutiérrez et al., (2012)

Microorganisms bring about most of the cellulose degradation occurring in nature. Cellulolytic microorganisms play an important role in recycling of cellulose which is the most abundant carbohydrate produced by plants. Cellulose is a simple polymer, that is insoluble, crystalline microfibrils, which are highly resistant to enzymatic hydrolysis. All organisms recognized to degrade cellulose efficiently by enzymes with different specificities Béguin et al., (1994).The first step of cellulose degradation of microbes includes enzymatic hydrolysis of the complex polymer using enzyme. Mostly, efficient cellulase activities are observed in fungi but bacteria have high growth rate as compared to fungi and has good potential for cellulase production Maki et al., (2011). The bacterial species capable of degrading cellulolytic materials which include Trichonympha, Clostridium, Actinomycetes, Bacteroides succinogenes, Butyrivibrio fibrisolvens,
Ruminococcus albus, Methanobrevibacter ruminantium Bacillus, Clostridium, Cellulomonas, Thermomonospora, Ruminococcus, Bacteroides, Erwinia, and Acetivibrio species Robson et al., (1989), Lee et al., (2008), Kim et al., (2009), Milala et al., (2005). Termites have a syntrophic symbiotic microflora responsible for cellulosic feed digestion in their guts Gupta et al., (2012) have isolated eight cellulose degrading bacteria using various invertebrates like termite, snail, caterpillar and bookworm for bioethanol production. Various scientists shown their interest in isolating cellulose degrading bacteria because of their massive applicability in industrial fields for the production of bioethanol, biomethanation and also for agricultural waste management

There are two types of degradation systems in fungi: intracellular, together with the outer cell envelope layer, and extracellular, vital for polysaccharide degradation Sánchez et al., (2009). Fungal strategies for delignification are substantially complex, most likely due to the high complexity of the raw materials. However, various groups of fungi like the soft-rot fungi (Aspergillus and Neurospora), brown-rot fungi (Coniophora, Postia placenta, Gloephyllum trabeum) and white-rot fungi (Phanerochaete chrysosporium, Pleurotus ostreatus) has shown promising degradation efficiency. Sasikumar et al., (2014) isolated nine lignin degrading fungi and indicated that Pseudomonas sp. has significant potential for use in the applications for the treatment of lignin degradation and lignin related environmental pollutants. There are a number of studies with regards to microbial biolignification. A detailed review of the biodegradation and bioconversion of lignocellulosic residues has been given by Sánchez et al., (2009). Amongst different raw materials used for isolating lignin degrading fungi, wood is a potential material for isolation since it has high hemicellulose and 
lignin content. During its decay or degradation, lignin degrading microorganisms predominate the process. Hence, the present study is to isolate and purify the lignocellulose degrading bacteria and fungi from various organic sources.

\section{Materials and Methods}

Collection of raw material for isolation of lignin and cellulose degrading bacteria and fungi

The samples like decomposed woods, tree twigs, fungal fruiting bodies from the degraded wood, degraded leaves, crop residue compost, termites, cowdung were selected as a source for isolation of lignin and cellulose degrading bacteria and fungi.

\section{Isolation of bacteria}

The termite gut and decaying leave samples were taken for the isolation of lignocellulolytic bacterial strain. Enrichment cultures were prepared for isolating the lignocellulolytic bacterial strain with minimal media. The decaying leaves samples were collected in and around Tamil Nadu Agricultural University campus, Coimbatore. The collected leaves were immersed in sterile minimal salt medium with Kraft lignin as sole carbon source and kept for incubation for 24 hrs. After $24 \mathrm{hrs}$ of incubation $1 \mathrm{ml}$ of the substrate were taken and serially diluted. The samples are then plated in the sterile petri plate containing nutrient agar medium and kept for incubation. The distinct individual colonies developed were further streaked separately to obtain pure culture.

Besides termites were used for isolating cellulose degrading bacteria and were macerated using pestle and mortar using sterile solution of $0.9 \% \mathrm{NaCl}$, then homogenized and centrifuged. The supernatant collected by macerating the termite gut was enriched in basal salt media $\left(\mathrm{NaNO}_{3}-2.5 \mathrm{~g} ; \mathrm{KH}_{2} \mathrm{PO}_{4}-2 \mathrm{~g} ; \mathrm{MgSO}_{4}-0.2 \mathrm{~g}\right.$; $\mathrm{NaCl}-0.2 \mathrm{~g} ; \mathrm{CaCl}_{2} \cdot 6 \mathrm{H}_{2} \mathrm{O}-0.1 \mathrm{~g}$ in a litre) containing filter paper strips for isolation of cellulolytic bacteria.

The enriched media were incubated at $37^{\circ} \mathrm{C}$ for 7 days at $100 \mathrm{rpm}$. The bacterial colonies capable of degrading cellulose source were isolated on a separate medium of cellulose agar medium with the composition of $\mathrm{KH}_{2} \mathrm{PO}_{4}$ - $0.5 \mathrm{~g}, \mathrm{MgSO}_{4}-0.25 \mathrm{~g}$, cellulose - $2.0 \mathrm{~g}$, agar $15 \mathrm{~g}$, gelatin- $2 \mathrm{~g}$ in 1 litre distilled water at $\mathrm{pH}$ 6.8-7.2.

For lignin degrading bacteria the decayed leave samples were incubated at minimal salt medium with Kraft lignin as sole carbon source for 48 hours. After incubation, $1 \mathrm{ml}$ of the solution was serially diluted and plated on the sterilized petriplate containing nutrient agar medium and incubated for 24 hours.

\section{Isolation of fungi}

Wood is a good source for isolating lignocellulose degrading fungi due to its high lignin content. Hence, wood samples which are at the brink of decaying were collected in and around Tamil Nadu Agricultural University campus, Coimbatore. The sample was collected in an air tight container and stored in refrigerator.The collected wood sample and fungal fruiting body were made into small pieces and sterilized by disinfecting using $0.1 \%$ sodium hypochlorite and rinsed with sterile water.

The sample were then directly placed in PDA medium (sliced potato-200 $\mathrm{g} \mathrm{L}^{-1}$, dextrose-20 $\mathrm{g} \mathrm{L}^{-1}$ and agar- $20 \mathrm{~g} \mathrm{~L}^{-1}$ ) and incubated for one week. The morphologically distinct fungal colonies developing from these substrates were further transferred to another sterile petriplate containing PDA medium. 
Pure culture of cellulose and lignin degrading bacteria and fungi

After isolating the cultures of bacteria and fungi, they were repeatedly streaked on freshly prepared medium to obtain individual colonies for obtaining pure culture.

Screening of isolated bacterial and fungal cultures for cellulolytic and lignolytic activity

\section{Bacteria}

The cellulosed degrading ability of their isolated bacterial cultures was confirmed by using $0.1 \%$ Congo-red solution. The Congored solution was flooded on the plates containing basal medium and kept for 15 mins. After, 15 mins the plates are washed with $\mathrm{NaCl}$ solution. The organism which shows the clearance zone is confirmed as cellulose degrading bacteria.

The isolated bacterial cultures were further screened using methylene blue dye as an indicator for lignolytic activity. The microbes that produce lignolytic enzymes undergo oxidation of indicator dye. The isolated bacteria were streaked on methylene blue indicator dye $\left(0.25 \mathrm{gL}^{-1}\right)$ containing LB agar plate. The plates were incubated at $30^{\circ} \mathrm{C}$ for 72 $\mathrm{h}$. the decolorization of methylene dye show the lignolytic activity of the isolated microbes

\section{Fungi}

Brilliant blue dye clearance test was used for the determination of lignin modifying enzymes in fungal culture isolated. Machado et al., (2005) found a positive correlation between discolouration of brilliant blue dye and production of lignin modifying enzymes. This agar clearance test gives clear results of qualitative data on peroxidase-type lignin modifying enzymes. The malt extract agar medium was prepared and supplemented with
$0.01 \% \mathrm{w} / \mathrm{v}$ Brilliant Cresyl Blue $(0.01 \mathrm{~g}$ in every $100 \mathrm{ml}$ of sterile distilled water), after which it was autoclaved. Aqueous glucose solution containing $20 \mathrm{~g}$ w/v of glucose was prepared to each $100 \mathrm{ml}$ of growth medium prepared, and $1 \mathrm{ml}$ of the aqueous glucose solution was aseptically added to the prepared Malt Extract Agar. The already prepared medium was then aseptically transferred to Petri dishes. The test fungus were inoculated on in petri dish and uninoculated plate served as control. They were later incubated at $25^{\circ} \mathrm{C}$ in darkness and examined for 10 days. The clearing of dye shows the production of lignin modifying enzyme.

\section{Results and Discussion}

Totally 20 bacterial colonies and 8 fungal colonies were isolated, from those 28 isolates, one cellulose degrading bacteria, one lignin degrading bacteria and two number of lignin degrading fungi were confirmed based on the qualitative test on the production of the cellulolytic and lignolytic enzyme activity. The strains that showed the positive results were multiplied and stored on the slant and preserved.

\section{Isolation and screening of cellulose and lignin degrading bacteria}

Cellulose degrading bacteria was isolated form the termite gut. Upon incubating the macerated termite gut in basal salt medium, a cloudy bacterial growth was observed after 5 days (Fig. 1). Fifteen bacteria were isolated and screened for cellulolytic activity using Congo - red agar media. Out of the fifteen bacterial isolates, only one bacterium succeeded by producing a clear zone (Fig. 2) indicating its potential to degrade cellulose. This is mainly production of cellulose enzyme. Similar results were recorded by Dillon et al., (2004), Wenzel et al., (2002), Delalibera et al., (2005) and Ramin et al., (2008). Prior surveys show that cellulose 
compounds, are degraded by bacteria during the passage of wood through the termite gut Kuhnigk et al., (1994), Kuhnigk et al., (1997). The cellulose agar medium or CMC as a carbon source used for screening cellulose degrading bacteria by developing zone of hydrolysis Gomashe et al., (2013), Das et al., (2014), Patagundi et al., (2014) and the results were correlated.

Decayed leaf samples were chosen for isolating lignin degrading bacteria. By inoculating the decayed leaf samples on the enriched MSM-L media with Kraft lignin as a sole carbon source, five bacterial colonies were isolated. While screening for the lignolytic activity, only one bacterial isolate out of the five, exhibited a positive result indicated by a decolourization on the selective agar media (Fig. 3). The predominant methylene blue decolorizers were Pseudomonas sp. upon characterization using standard protocol.Ferreira-Leitão et al., (2007) used methylene blue dye as an indicator to identify the decolorization of isolated microbes and the comparable results were recorded by Sasikumar et al., (2014).

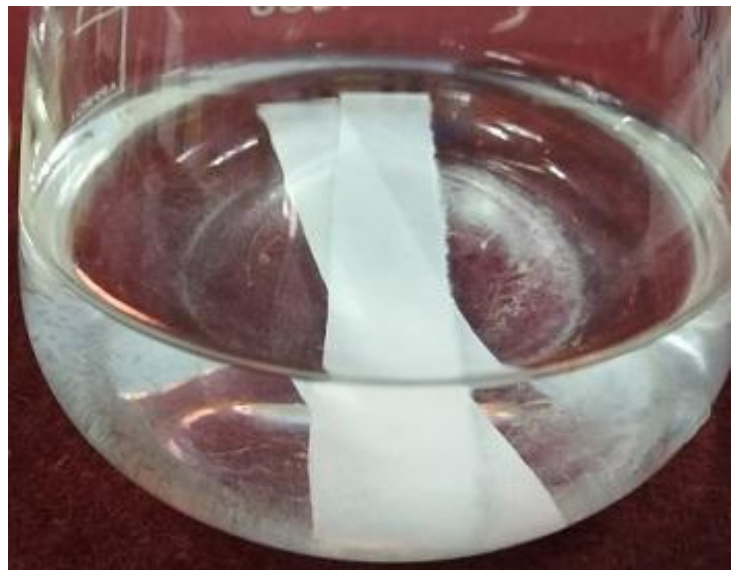

Control

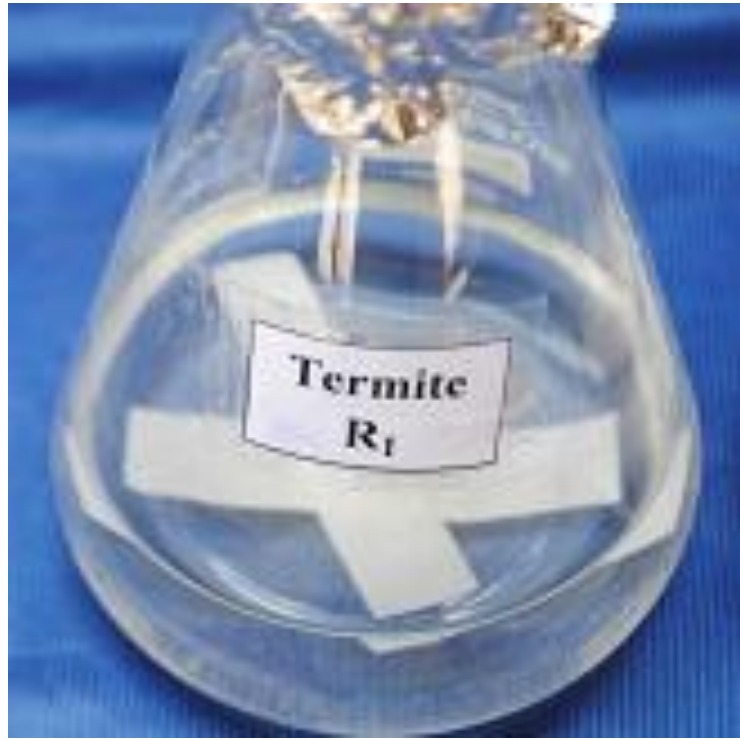

Before incubation

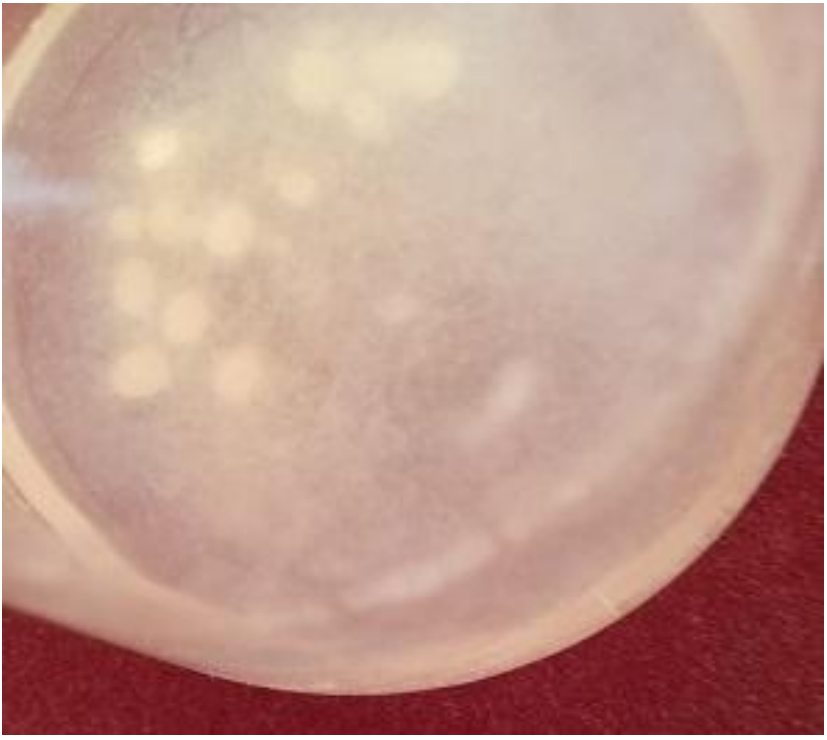

After incubation

Fig.1 Enrichment of macerated termite gut in the basal salt medium for isolation of cellulose degrading bacteria 


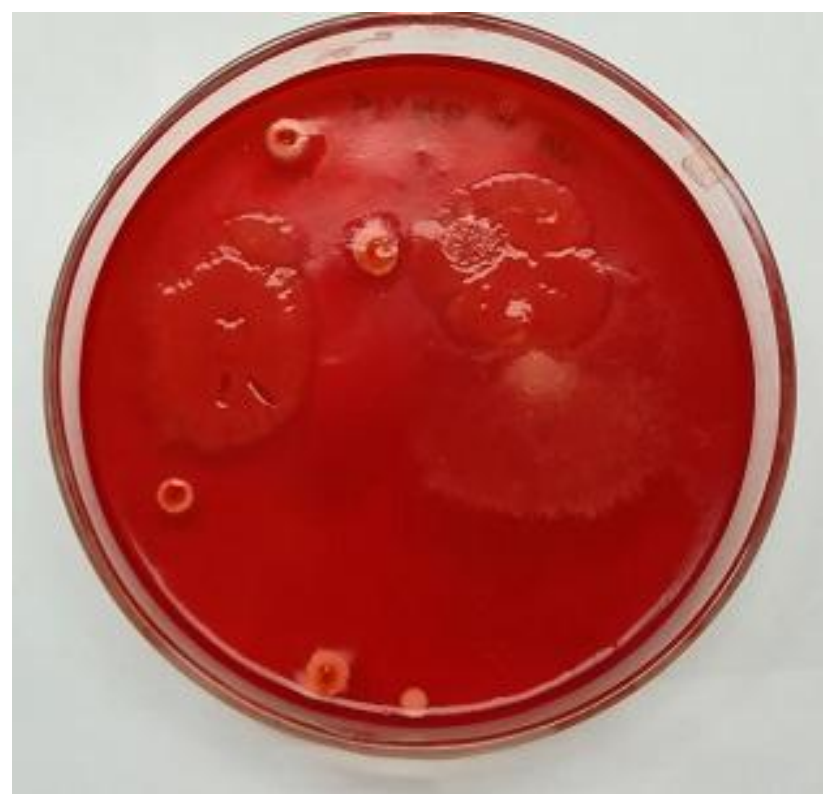

Fig.2 Celluose degrading bacteria isolated from termite gut (Clear zone around the colonies)

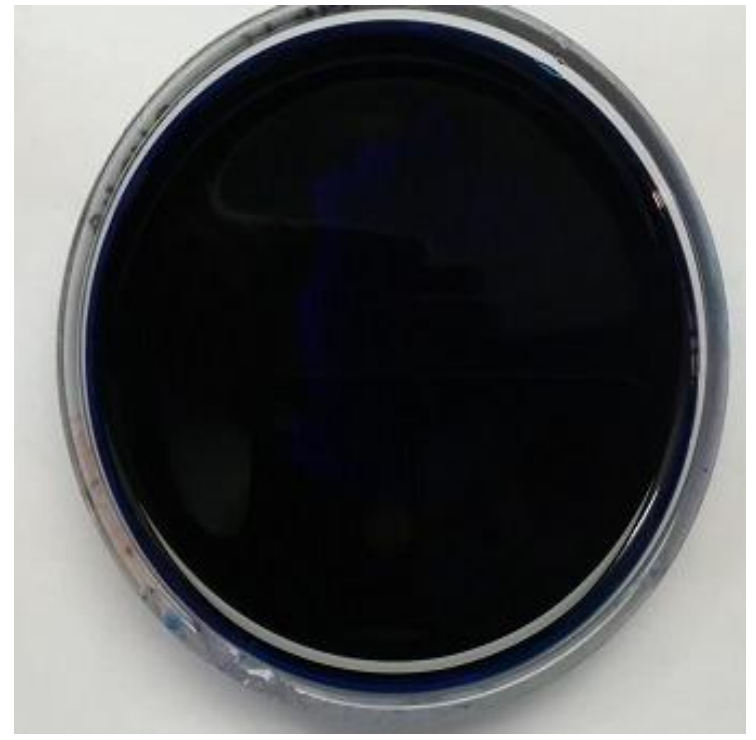

Control

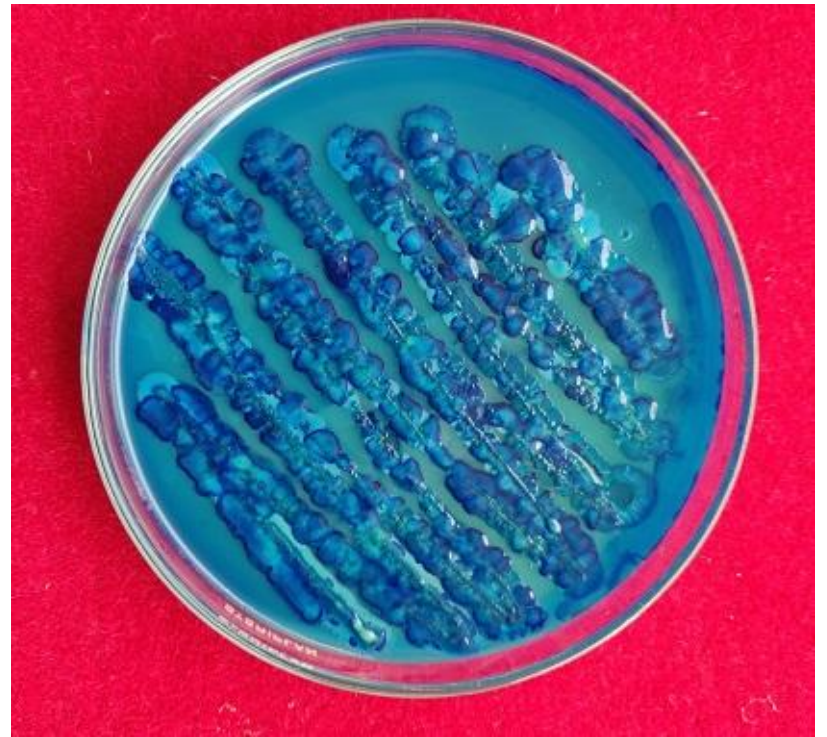

Decolorization zone (Lignolytic activity)

Fig.3 Lignin degrading bacteria isolated from decayed leaf samples

Isolation and screening of lignin degrading fungi

The decayed wood has inhabited large number of fungal isolates that degrades lignocellulosic waste materials. Totally eight fungal strains were isolated from the decayed wood samples using PDA medium. They were screened for lignin degradation with brilliant blue dye. Among them, the two fungal cultures which showed the discoloration were selected, purified and maintained in Czapekdoz broth and PDA slant. The correlation between decolourisation of dyes and ligninolytic abilities of fungi has been established by several authors Gutiérrez et al., (2012), Babic et al., (2007), Sarnthima et al., (2009), Singh et al., (2010), Barrasa et al., (2014). The lignolytic ability of isolated fungal strains used in this study is in 
correlated with the information given by Dill et al., (1986), Tychanowicz et al., (2004), Adejoye et al., (2009), Ramin et al., (2008), Liers et al., (2010). The decolourization of methylene blue dye is due to the secretion of extracellular lignolytic enzymesBaldrian et al., (2004) andSchmidt et al., (2005). The isolated 2 bacterial and 2 fungal strains were identified as Pseudomonas sp. and Aspergillus sp. having significant potential for using them in the treatment of lignin and cellulose degradation.

In this study, two bacterial and two fungal isolates having the ability to degrade lignocellulosic waste materials were identified. Being a preliminary study, further studies are required for better understanding of the mechanisms and enzymes involved in the processes are important in converting the lignocellulosic biomass into other valueadded end products such as biofuel, sugar productions and management of waste to wealth.

\section{References}

Adejoye, O. D., and Fasidi, I. O. (2009). Biodegradation of agro-wastes by some Nigerian white-rot fungi. BioResources, 4 (2), 816-824.

Babic, J., and Pavko, A. (2007). Production of ligninolytic enzymes by Ceriporiopsis subvermispora for decolourization of synthetic dyes. Acta chimica slovenica, 54 (4), 730.

Baldrian, P. (2004). Increase of laccase activity during interspecific interactions of white-rot fungi. Fems microbiology ecology, 50 (3), 245-253.

Barrasa, J. M., Blanco, M. N., EsteveRaventós, F., Altés, A., Checa, J., Martínez, A. T., and Ruiz-Dueñas, F. J. (2014). Wood and humus decay strategies by white-rot basidiomycetes correlate with two different dye decolorization and enzyme secretion patterns on agar plates. Fungal genetics and biology, 72, 106-114.

Béguin, P., and Aubert, J.-P. (1994). The biological degradation of cellulose. FEMS Microbiology Reviews, 13 (1), 25-58.

Das, P., Solanki, R., and Khanna, M. (2014). Isolation and screening of cellulolytic actinomycetes from diverse habitats. International Journal of Advanced Biotechnology and Research, 5 (3), 438-451.

Dill, I., and Kraepelin, G. (1986). Palo podrido: model for extensive delignification of wood by Ganoderma applanatum. Appl. Environ. Microbiol., 52 (6), 1305-1312.

Dillon, R., and Dillon, V. (2004). The gut bacteria of insects: nonpathogenic interactions. Annual Reviews in Entomology, 49 (1), 71-92.

Ferreira-Leitão, V. S., de Carvalho, M. E. A., and Bon, E. P. (2007). Lignin peroxidase efficiency for methylene blue decolouration: comparison to reported methods. Dyes and Pigments, 74 (1), 230-236.

Gomashe, A., Gulhane, P., and Bezalwar, P. (2013). Isolation and screening of cellulose degrading microbes from nagpur region soil. International Journal of Life Sciences, 1 (4), 291-293.

Gutiérrez, A., Rencoret, J., Cadena, E. M., Rico, A., Barth, D., José, C., and Martínez, Á. T. (2012). Demonstration of laccase-based removal of lignin from wood and non-wood plant feedstocks. Bioresource technology, 119, 114-122.

Kamm, B., and Kamm, M. (2004). Principles of biorefineries. Applied microbiology and biotechnology, 64 (2), 137-145.

Kim, B.-K., Lee, B.-H., Lee, Y.-J., Jin, I.-H., Chung, C.-H., and Lee, J.-W. (2009). Purification and characterization of carboxymethylcellulase isolated from a 
marine bacterium, Bacillus subtilis subsp. subtilis A-53. Enzyme and Microbial Technology, 44 (6-7), 411416.

Kuhnigk, T., Borst, E.-M., Ritter, A., Kämpfer, P., Graf, A., Hertel, H., and König, H. (1994). Degradation of lignin monomers by the hindgut flora of xylophagous termites. Systematic and Applied Microbiology, 17 (1), 76-85.

Kuhnigk, T., and König, H. (1997). Degradation of dimeric lignin model compounds by aerobic bacteria isolated from the hindgut of xylophagous termites. Journal of basic microbiology, 37 (3), 205-211.

Lee, Y.-J., Kim, B.-K., Lee, B.-H., Jo, K.-I., Lee, N.-K., Chung, C.-H.,... Lee, J.-W. (2008). Purification and characterization of cellulase produced by Bacillus amyoliquefaciens DL-3 utilizing rice hull. Bioresource technology, 99 (2), 378-386.

Liers, C., Bobeth, C., Pecyna, M., Ullrich, R., and Hofrichter, M. (2010). DyP-like peroxidases of the jelly fungus Auricularia auricula-judae oxidize nonphenolic lignin model compounds and high-redox potential dyes. Applied microbiology and biotechnology, 85 (6), 1869-1879.

Maki, M. L., Broere, M., Leung, K. T., and Qin, W. (2011). Characterization of some efficient cellulase producing bacteria isolated from paper mill sludges and organic fertilizers. International journal of biochemistry and molecular biology, 2 (2), 146.

Mosier, N., Wyman, C., Dale, B., Elander, R., Lee, Y., Holtzapple, M., and Ladisch, M. (2005). Features of promising technologies for pretreatment of lignocellulosic biomass. Bioresource technology, 96 (6), 673-686.

Patagundi, B. I., Shivasharan, C., and Kaliwal, B. (2014). Isolation and characterization of cellulase producing bacteria from soil. International Journal of Current Microbiology and Applied Sciences, 3 (5), 59-69.

Ragauskas, A. J., Williams, C. K., Davison, B. H., Britovsek, G., Cairney, J., Eckert, C. A., and Liotta, C. L. (2006). The path forward for biofuels and biomaterials. science, 311 (5760), 484-489.

Ramin, M., Alimon, A., Sijam, K., and Abdullah, N. (2008). Filter paper degradation by bacteria isolated from local termite gut. Research Journal of Microbiology, 3 (8), 565-568.

Robson, L. M., and Chambliss, G. H. (1989). Cellulases of bacterial origin. Enzyme and Microbial Technology, 11 (10), 626-644.

Sarnthima, R., Khammuang, S., and Svasti, J. (2009). Extracellular ligninolytic enzymes by Lentinus polychrous Lév. under solid-state fermentation of potential agro-industrial wastes and their effectiveness in decolorization of synthetic dyes. Biotechnology and Bioprocess Engineering, 14 (4), 513522.

Sasikumar, V., Priya, V., Shankar, C. S., and Sekar, D. S. (2014). Isolation and preliminary screening of lignin degrading microbes. Journal of Academia and Industrial Research, 3 (6), 291-294.

Schmidt, K. R., Chand, S., Gostomski, P. A., H. Boyd- Wilson, K. S., Ford, C., and Walter, M. (2005). Fungal inoculum properties and its effect on growth and enzyme activity of Trametes versicolor in soil. Biotechnology progress, 21 (2), 377-385.

Sergentani, A. G., Gonou-Zagou, Z., Kapsanaki-Gotsi, E., and Hatzinikolaou, D. G. (2016). Lignocellulose degradation potential of Basidiomycota from Thrace (NE Greece). International 
Biodeterioration and Biodegradation, 114, 268-277.

Singh, P., Sulaiman, O., Hashim, R., Rupani, P., and Peng, L. C. (2010). Biopulping of lignocellulosic material using different fungal species: a review. Reviews in Environmental Science and Bio/Technology, 9 (2), 141-151.

Tychanowicz, G. K., Zilly, A., de Souza, C. G. M., and Peralta, R. M. (2004). Decolourisation of industrial dyes by solid-state cultures of Pleurotus pulmonarius. Process Biochemistry, 39 (7), 855-859.

Wenzel, M., Schönig, I., Berchtold, M., Kämpfer, P., and König, H. (2002). Aerobic and facultatively anaerobic cellulolytic bacteria from the gut of the termite Zootermopsis angusticollis. Journal of applied microbiology, 92 (1), $32-40$.

\section{How to cite this article:}

Keerthana, S., P. Kalaiselvi, M. Maheshwari and Kalaiselvi, T. 2019. Isolation and Screening of Lignin and Cellulose Degrading Proficient Microbial Strains from Diverse Biotic Substrates Based on Qualitative Traits. Int.J.Curr.Microbiol.App.Sci. 8(07): 475-483. doi: https://doi.org/10.20546/ijcmas.2019.807.058 